Research Article

\title{
Zinc Oxide Phytonanoparticles' Effects on Yield and Mineral Contents in Fruits of Tomato (Solanum lycopersicum L. cv. Cherry) under Field Conditions
}

\author{
Federico Antonio Gutiérrez-Miceli ${ }^{D},{ }^{1}$ María Ángela Oliva-Llaven (D), ${ }^{2}$ \\ María Celina Luján-Hidalgo, ${ }^{1}$ María Concepción Velázquez-Gamboa, ${ }^{1}$ \\ Daniel González-Mendoza, ${ }^{3}$ and Yazmin Sánchez-Roque $\mathbb{i D}^{4}$

\begin{abstract}
${ }^{1}$ Plant Tissue Culture Laboratory, Tecnológico Nacional de México/I.T. de Tuxtla Gutiérrez, Carretera Panamericana Km 1080, Terán, C.P., Tuxtla Gutiérrez 29050, Chiapas, Mexico

${ }^{2}$ Facultad de Medicina Veterinaria y Zootecnia, Universidad Autónoma de Chiapas, Copainalá, Chiapas, Mexico

${ }^{3}$ Instituto de Ciencias Agrícolas, Universidad Autónoma de Baja California (ICA-UABC), Carretera a Delta S/N C.P., Ejido, Nuevo León 21705, Baja California, Mexico

${ }^{4}$ Research Laboratory, Universidad Politécnica de Chiapas, Carretera Tuxtla-Villaflores Km 1+500, Las Brisas, C.P., Suchiapa 29150, Chiapas, Mexico
\end{abstract}

Correspondence should be addressed to Yazmin Sánchez-Roque; ysanchez@ia.upchiapas.edu.mx

Received 11 February 2021; Revised 14 May 2021; Accepted 27 May 2021; Published 11 June 2021

Academic Editor: Tariq Mahmood

Copyright (C) 2021 Federico Antonio Gutiérrez-Miceli et al. This is an open access article distributed under the Creative Commons Attribution License, which permits unrestricted use, distribution, and reproduction in any medium, provided the original work is properly cited.

\begin{abstract}
The use of phytonanoparticles in agriculture could decrease the use of fertilizers and therefore decrease soil contamination, due to their size being better assimilated in plants. It is important to mention that the nanofertilizer is slow-releasing and improves plant physiological properties and various nutritional parameters. The influence of soil and foliar applications of phytonanoparticles of $\mathrm{ZnO}$ with the Moringa oleifera extract under three concentrations $(25,50$, and $100 \mathrm{ppm}$ ) was evaluated on the cherry tomato crop (Solanum lycopersicum L.). Synthesis of the phytonanoparticles was analyzed with ultraviolet-visible spectroscopy (UV-Vis) and infrared transmission spectroscopy with Fourier transform (FT-IR), as well as the analysis with the dynamic light scattering (DLS) technique. The morphometric parameters were evaluated before and after the application of the nanoparticles. The minerals' content of fruits was done 95 days after planting. Results showed that soil application was better at a concentration of $25 \mathrm{ppm}$ of phytonanoparticles since it allowed the greatest number of flowers and fruits on the plant; however, it was demonstrated that when performing a foliar application, the fruit showed the highest concentrations for the elements $\mathrm{Mg}, \mathrm{Ca}$, and $\mathrm{Na}$ at concentrations of 511,4589 , and $223 \mathrm{mg} \mathrm{kg}^{-1}$, respectively.
\end{abstract}

\section{Introduction}

The application of fertilizers has increased food production considerably; however, the intensive use of these significantly threatens environmental health and ecosystem functions. Most of the fertilizers are not available to plants due to run-off and cause pollution. Fertilizers coated in nanomaterials can solve this problem [1]. The bionanoparticles' synthesis is an ecologically sound and sustainable alternative to the conventional methods, in as much as bionanoparticles can use easily available bio-resource from the leafs extract of a plant, such as the case of phytonanoparticles (NPs). The use of practically nontoxic natural extracts allows the green synthesis of NPs and being used in sensitive areas, such as agriculture [2]. Nanocatalysis represents nowadays an innovative approach to obtain better properties due to stable activity and good selectivity [3].

In addition, zinc oxide is currently used as an antimicrobial agent in micro- and nanoscale formulations; these nanoparticles could be used in agriculture as a plant protector 
against pathogens and in fertilizer products as micronutrients [4]. This formulation could bring benefits for plants and/or edible crops [5] of economic importance such as the tomato (Solanum lycopersicum L.). Specifically, the cherry tomato is characterized by small fruits with different sizes, colors, and flavors. It is currently in high demand in restaurants and bars and in the manufacture of various dishes as gourmet snacks [5].

Mineral's uptake in adequate levels plays important role in growth, yield, and quality attributes of tomato and also contains antioxidant compounds important for human health; however, in recent years, a deficiency of mineral elements of up to $80-90 \%$ has been observed in fruits. This can be attributed to conventional agricultural techniques [4].

Therefore, given this deficiency present in tomato plants and fruits, the present research aimed to evaluate the effect of $\mathrm{ZnO}$ phytonanoparticles with aqueous extract of Moringa oleifera on the accumulation of mineral elements in tomato plant fruits (Solanum lycopersicum L.) through an edaphic and foliar application.

\section{Materials and Methods}

2.1. Experimental Area. The experiment was carried out at the Ranch "El capricho divino" located in the municipality of Suchiapa, Chiapas, Mexico, located at $16^{\circ} 37^{\prime} 30^{\prime \prime}$ north latitude and $93^{\circ} 6^{\prime} 0^{\prime \prime}$ west longitude, at an altitude of $500 \mathrm{~m}$ above sea level, with warm subhumid climate and periodic rains; the average annual temperature in the municipal seat is $24.4^{\circ} \mathrm{C}$, with a rainfall of $956 \mathrm{~mm}$ per year.

2.2. Green Synthesis of Nanoparticles. The methodology described by [6] with some modifications was used, so $15 \mathrm{~mL}$ of the aqueous extract of Moringa oleifera was added to $1.64 \mathrm{~g}$ of zinc $\left(\mathrm{ZnSO}_{4}\right)$; the reaction mixture was kept under stirring for $6 \mathrm{~h}$ and, subsequently, $2 \mathrm{~m}$ of $\mathrm{NaOH}$ was added to the solution and placed in an incubator at $60^{\circ} \mathrm{C}$ with constant shaking for $12 \mathrm{~h}$. The colloidal solution was centrifuged at $4500 \mathrm{rpm}$ for $20 \mathrm{~min}$, and the precipitate was subjected to two consecutive washes with $96 \%$ ethanol and distilled water. Finally, the precipitate was dried in an oven at $50^{\circ} \mathrm{C}$ and a fine powder was obtained with the help of a mortar.

2.3. Physicochemical Characterization of Green Nanoparticles. The identification of the production of the $\mathrm{ZnO}$ phytonanoparticles was first evaluated by the color change of the aqueous solution of $M$. oleífera by Abdelmoteleb et al. [7].

For the characterization of $\mathrm{ZnO}$ phytonanoparticles, ultraviolet-visible spectroscopy (UV-Vis) and infrared transmission spectroscopy with Fourier transform (FT-IR) were first carried out. This was verified by performing a spectral scan of the colloidal solution in a range of $300-700 \mathrm{~nm}$ in a UV-Vis spectrophotometer (Beckman Coulter, USA), calibrated with a $\mathrm{ZnSO}_{4}$ solution $(0.34 \mathrm{~m})$ [7]. Likewise, the presence of the bands corresponding to the zinc metallic bonds in the phytonanoparticles was identified with an infrared spectroscope (NICOLET, Wisconsin, USA).

The size of the phytonanoparticles and the zeta potential were analyzed in solution using a nanotrac wave instrument
(Microtrac, Montgomeryville PA, USA) according to Mendez-Trujillo et al. [8]. Measurements were made using the dynamic light scattering (DLS) technique in a range of $0.1-1000 \mu \mathrm{m}$ at $25^{\circ} \mathrm{C}$, with a laser wavelength of $780 \mathrm{~nm}$ and a scattering angle of 90 Åã. Data obtained from DLS was analyzed using Microtrac FLEX operating software [9-11].

2.4. Experiment Establishment. The crop used was Solanum lycopersicum L. cv cherr. Five rows were planted with 100 seedlings each, the cultivation had a drip irrigation system and tensioned ropes in order to support the stem in its development in a $1 / 2$ ha antiaphid house. During their growth, phytonanoparticles of zinc oxide were applied in different concentrations $(0,25,50$, and $100 \mathrm{ppm})$ applying edaphically under the irrigation lines of the crop and in a foliar way through the use of a sprinkler; the first row was omitted or the first seedling of each row to decrease the ambient noise factor, and the treatments were applied once a week for 3 weeks.

Morphometric parameters in relation to the growth of the crop, such as plant height, number of fruits, and number of flowers, were evaluated before and after the application of the nanoparticles every 10 days for 60 days [5, 12].

2.5. Fruit Characterization. The fruits were characterized followed by the first harvest in a time of 95 days after planting. The method used was an adaptation of method 3052 described by U.S. EPA (Environmental Protection Agency), where $300 \mathrm{mg}$ of the dried and pulverized plant material was subjected to acid digestion with $9 \mathrm{~mL}$ of nitric acid, $2 \mathrm{~mL}$ of $30 \%$ hydrogen peroxide, and $1 \mathrm{~mL}$ of hydrochloric acid at $180^{\circ} \mathrm{C}$ until total digestion of the plant material [13]. After the digestion, the samples were filtered by Whatman No. 40 paper and graduated to $25 \mathrm{~mL}$. The minerals quantification was performed using plasma emission spectrometry (ICP-OES) (Perkin Elmer, Kyoto, Japan).

The total soluble solids in the fruits were determined using a digital refractometer. Fruits were sampled in triplicate of each treatment (each sample one gram) [14, 15].

\section{Results and Discussion}

3.1. Physicochemical Characterization of Green Nanoparticles. During the green synthesis of zinc oxide nanoparticles using the aqueous extract of Moringa oleifera, a change in coloration was observed in the extract on contact with the $\mathrm{ZnSO}_{4}$ solution, due to the reduction of $\mathrm{Zn}^{+2}$ to $\mathrm{Zn}^{0}$ (Figure 1).

The UV-Vis absorption spectrum of the colloidal solution is shown in Figure 2(a), the solid line corresponds to the plant extract of Moringa oleifera, and absorption peaks were observed approximately between 300 and $350 \mathrm{~nm}$. On the contrary, the dotted line corresponds to the spectrum of absorption of the phytonanoparticle solution, highlighting the absorption peak at approximately $400 \mathrm{~nm}$. Also, the IR adsorption spectrum of the dry $\mathrm{ZnO}$ phytonanoparticles is presented in Figure 2(b), adsorption bands were identified at 3390 and $2825 \mathrm{~cm}^{-1}$, and these bands are characteristic of the vibrations by stretching of the $\mathrm{O}-\mathrm{H}$ and $\mathrm{C}-\mathrm{H}$ bonds, 


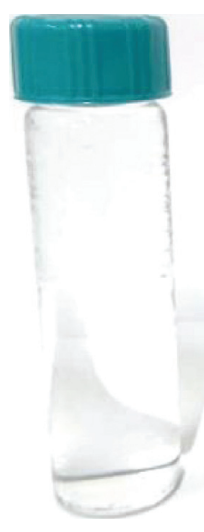

(a)



(b)

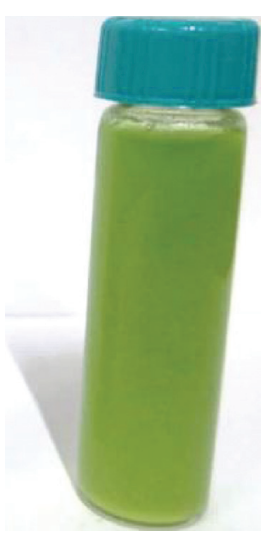

(c)

FIgURE 1: Colloidal solution of phytonanoparticles from the aqueous extract of Moringa oleifera: (a) $\mathrm{ZnSO}_{4}$ solution, (b) Moringa oleifera extract, and (c) $\mathrm{ZnO}$ phytonanoparticles after 12 hours of incubation at $60^{\circ} \mathrm{C}$.

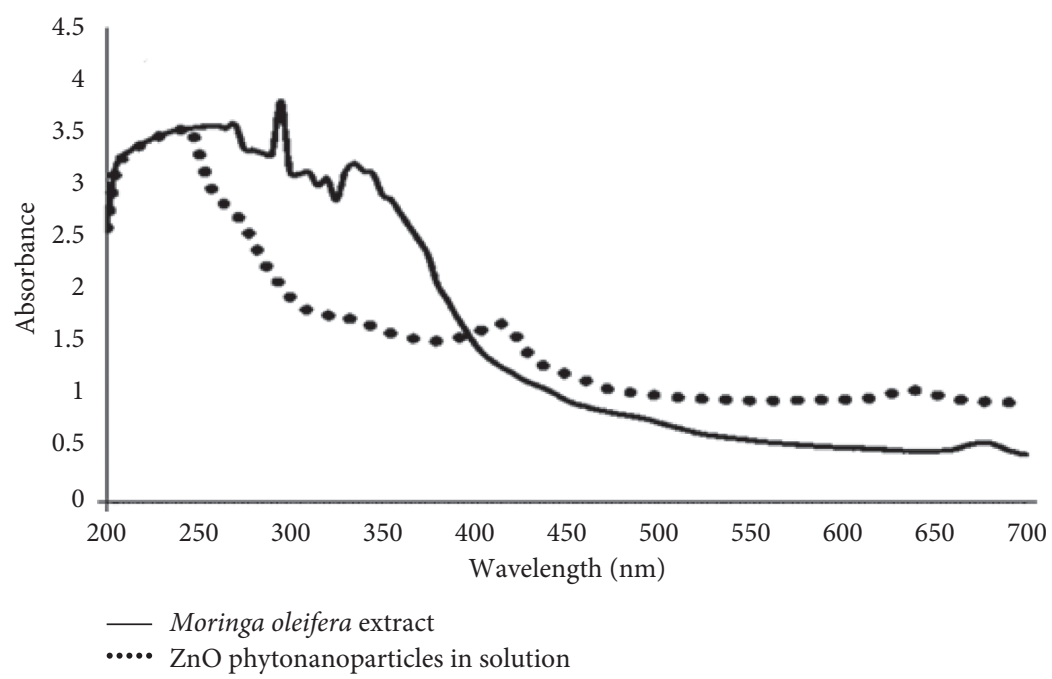

(a)

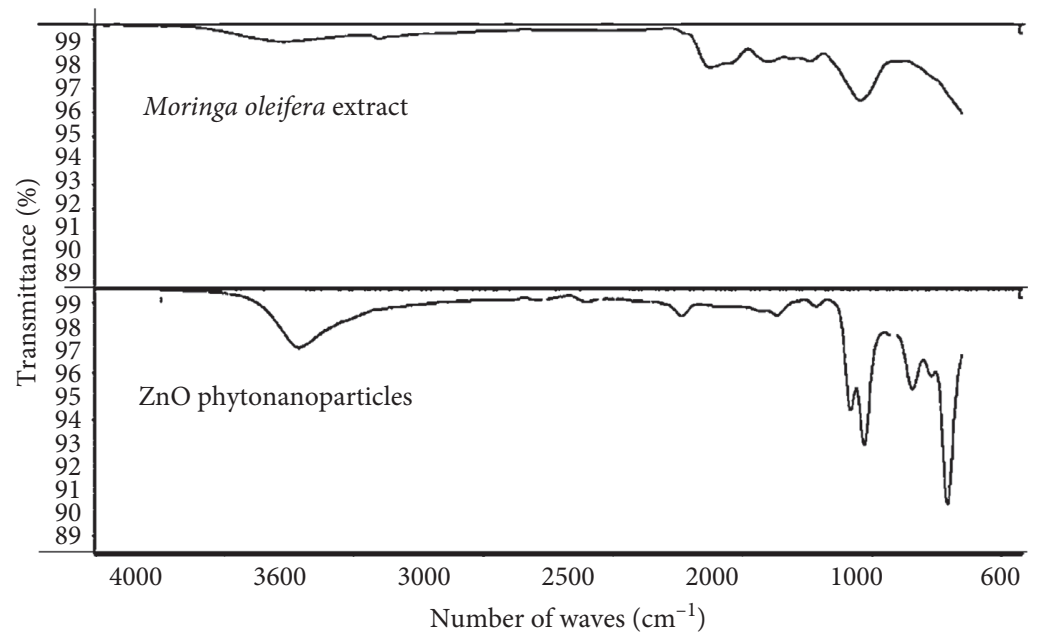

(b)

FIGURE 2: Characterization of $\mathrm{ZnO}$ phytonanoparticles with the aqueous extract of Moringa oleifera: (a) UV-Vis absorption spectrum and (b) FT-IR absorption spectrum. 
respectively. The band at $1830 \mathrm{~cm}^{-1}$ can be attributed to the asymmetric and symmetrical stretching of zinc carboxylates [16], while the band at $871 \mathrm{~cm}^{-1}$ is due to the stretching vibrations of the O- $\mathrm{Zn}$ bonds [17].

The DLS results for particle size in the solution of $\mathrm{ZnO}$ phytonanoparticles are presented in Figure 3. The results showed that $\mathrm{ZnO}$ NPs from $M$. oleifera form agglomerates with an average hydrodynamic size of $13 \mathrm{um}$ and zeta potential value of $22.56 \mathrm{mV}$, when dispersed in water.

The synthesis of $\mathrm{ZnO}$ phytonanoparticles from $M$. oleifera was confirmed by the change of color from dark green to light green color suggesting that $\mathrm{ZnSO}_{4}$ dissociates from $\mathrm{Zn}^{+2}$ to $\mathrm{Zn}^{0}$ by reduction action of phytochemicals present in $M$. oleifera phytonanoparticles. This behavior was similar to that reported by Ruiz-Romero et al. [18], who attributed the change in hue in the solution to the formation of zinc oxide nanoparticles.

During the UV-Vis absorption analysis of the aqueous extract of $M$. oleifera extract, peaks between 300 and $350 \mathrm{~nm}$ were identified (Figure 2(a)). These peaks correspond to the light absorption of the $\pi$ bonds of the benzene rings of the phenolic compounds present in the extract [19], while the absorption spectrum of phytonanoparticles in the solution presented a band of maximum absorption at $400 \mathrm{~nm}$ (Figure 2(b)). These irregularities are associated with chemical modifications with the reduction of metal ions and the oxidation of antioxidant compounds [20].

The zeta potential is an important characteristic that must be known about phytonanoparticles, since this characteristic influences other of equal importance, such as saturation solubility, dissolution rate, physical stability, and even biological performance [21]. A minimum of zeta potential $(+25 \mathrm{mV}$ or $-25 \mathrm{mV})$ demonstrates stable nanostructures [22]. As the zeta potential approaches " 0 " or the zero charge point, the attraction between the nanomaterials exceeds the repulsive forces between the structures resulting in agglomeration. The zeta potential values for the $\mathrm{ZnO}$ phytonanoparticles obtained in the present study indicate long-term stability of the colloids; this could be attributed to the presence of bioactive components in the aqueous extract of $M$. oleifera which covers the nanoparticles, stabilizing them.

\subsection{Evaluation of Morphometric Parameters of Tomato Plants.} The height of the tomato plants was evaluated as a morphometric variable, and greater growth was observed in terms of the application of the phytonanoparticles on the root at a concentration of $50 \mathrm{ppm}$; however, no significant statistical differences are seen with the control treatment (Figure $4 \mathrm{HE}-\mathrm{HF}$ ). Since zinc nanoparticles have shown to induce free radical formation, resulting in increased malondialdehyde and lower levels of reduced glutathione and reduced chlorophyll contents [8], this significantly impacts photosynthesis processes limiting development.

Likewise, the influence of phytonanoparticles on flower production was evaluated; specifically, a significant increase is observed in the treatment that applies $25 \mathrm{ppm}$ of phytonanoparticles through the root, producing a total of 23 flowers and showing significant statistical differences with the rest of the treatments. However, it is important to mention that according to the edaphic application of phytanoparticles, a decrease in flowering was observed as the concentration of applied phytonanoparticles increased (Figure 4, FE-FF) (Table 1).

So too, soil application of phytonanoparticles resulted in the highest fruit number per plant, since it allowed the production of 48 fruits at 15 days at a concentration of $100 \mathrm{ppm}$, demonstrating significant statistical differences with the rest of the treatments and the control (Figure 4, FRE-FRF) (Table 1). As was demonstrated by García-López et al. [11] who evaluated $\mathrm{ZnO}$ nanoparticles, they mentioned that application of $\mathrm{ZnO}$ phytonanoparticles (NPs) could be employed in habanero pepper production to improve yield and quality, but it is still unknown nutraceutical properties of fruits.

However, Santhoshkumar et al. [10] evaluated the use of nanoparticles of Moringa oleifera; they identified that the green synthesis of phytonanoparticles significantly improves the flowering and fruiting of crops, as observed in this research paper (Figure 4). The use of plant materials for green synthesis contains certain bioactive compounds like flavonoids, phenols, citric acid, ascorbic acid, polyphenolic, terpenes, alkaloids, and reductase which act as reducing agents. Plant-mediated synthesis of nanoparticles is a very promising area of nanotechnology because the plant itself acts as both a reducing and capping agent $[4,19]$.

The promoter effect could be related to the zinc role as a precursor in the synthesis of auxins that promote cell division, as well as its influence on the reactivity of indoleacetic acid, which functions as a hormonal phytostimulant $[8,13,17,18]$. Furthermore, it is possible that $\mathrm{ZnO}$ nanoparticles could be involved in a greater production of the phytohormones cytokine and gibberellin, apart from inducing the activity of antioxidant enzymes [23].

Likewise, Santos-Espinoza et al. [24] indicated that the mechanisms by which peanut plants respond positively to the application of nanoparticles were an increase in the activity of phenylalanine ammonia-lyase and antioxidant enzyme. They revealed a significant decrease in indole- 3 acetic acid and induced the synthesis of gibberellins; the improvement in the quality of peanut fruits was demonstrated.

Abdelmoteleb et al. [7], mentioned that nanoparticles have great benefits in agriculture, since the phytocomposites nanoencapsulated help in slow and sustained release of nutrients and agrochemicals resulting in precise dosage to the plants because of holding the material more strongly from the plant due to higher surface tension of nanoparticles than conventional surfaces.

3.3. Fruit Characterization. After the harvest, the effect of the phytonanoparticles applied in the root and on the leaves at different concentrations was evaluated on the bioaccumulation of chemical elements in the fruits. Soil application at $25 \mathrm{ppm}$ level showed a statistically significant difference in the accumulation of magnesium compared to 


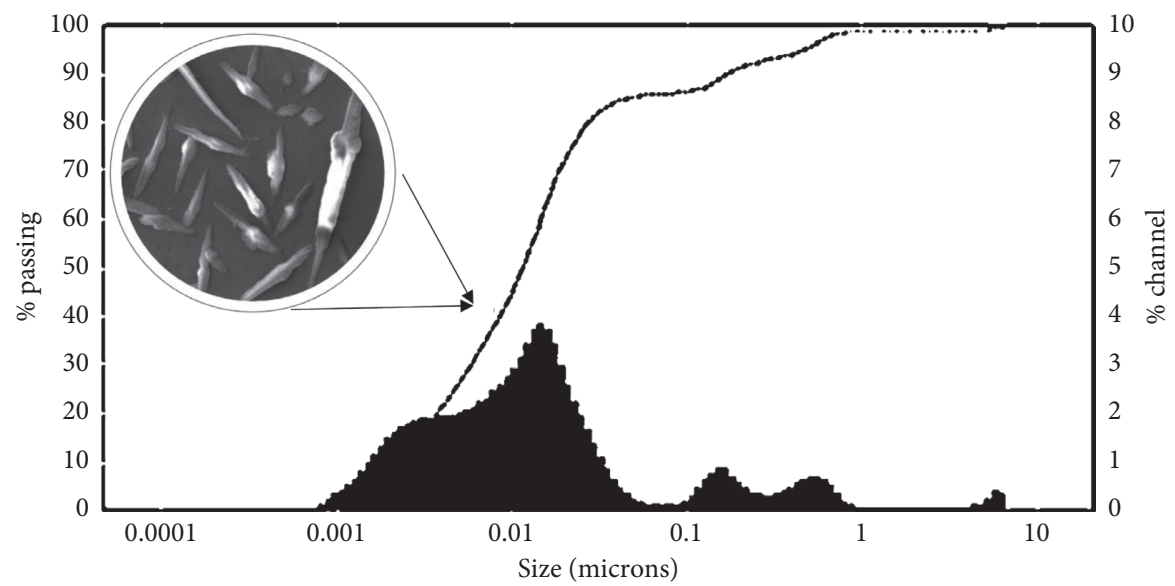

Figure 3: Particle size distribution of ZnO NPs-M. oleifera using dynamic light scattering (DLS) measurements.

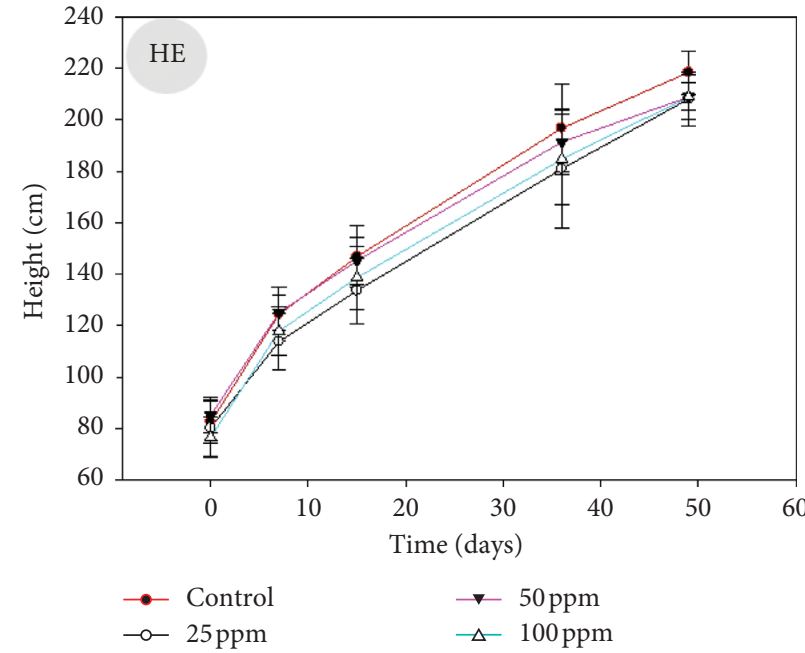

(a)

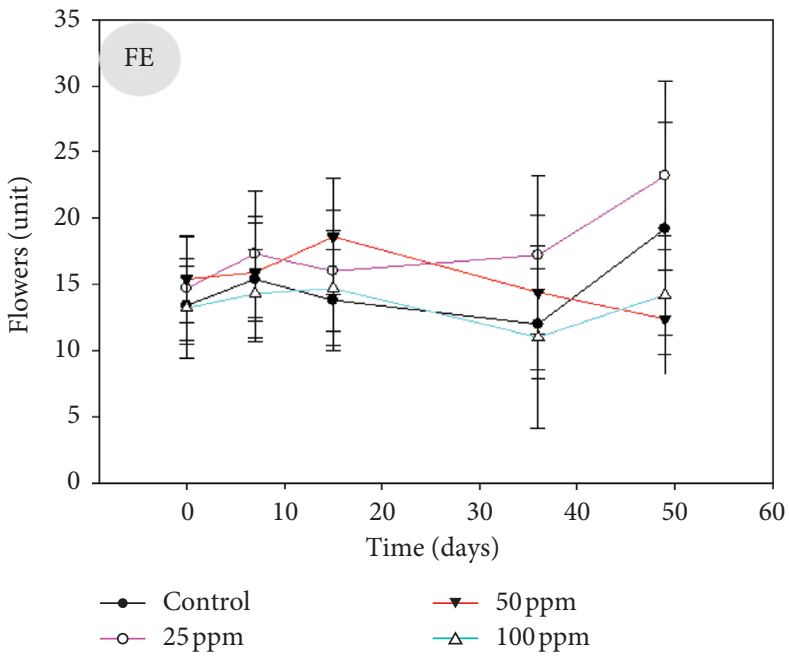

(c)



(b)

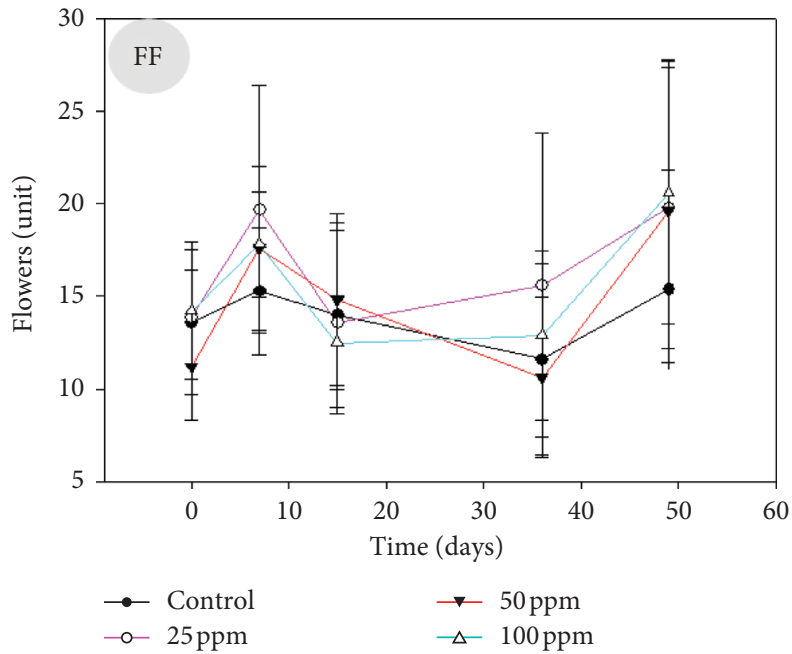

(d)

FIgURE 4: Continued. 




(e)



(f)

Figure 4: Evaluation of morphometric variables of the effect of $\mathrm{ZnO}$ phytonanoparticles with the Moringa oleifera extract on the tomato plants (Solanum lycopersicum). Mean of three repetitions with standard error. HE: height/edaphic; HF: height/foliar; FE: flowering/edaphic; FF: flowering/foliar; FRE: fruiting/edaphic; FRF: fruiting/foliar.

TABLE 1: Percentage analysis of the increase or decrease of the morphometric variables, accumulation of elements, and total soluble solids, depending on the effect of phytonanoparticles on tomato plants and fruits (Solanum lycopersicum).

\begin{tabular}{|c|c|c|c|c|c|c|c|c|}
\hline \multirow{3}{*}{ Concentration (ppm) } & \multicolumn{4}{|c|}{ Morphometric variables' evaluation (\%) } & & & \multirow{2}{*}{\multicolumn{2}{|c|}{$\begin{array}{c}\text { Total soluble solids' } \\
\text { evaluation }(\%)\end{array}$}} \\
\hline & \multicolumn{2}{|c|}{ Height } & \multicolumn{2}{|c|}{ Flowering } & \multicolumn{2}{|c|}{ Fruiting } & & \\
\hline & $\mathrm{E}$ & $\mathrm{F}$ & $\mathrm{E}$ & $\mathrm{F}$ & $\mathrm{E}$ & $\mathrm{F}$ & $\mathrm{E}$ & $\mathrm{F}$ \\
\hline 25 & $-9.09^{*}$ & -10 & +51.17 & +38.46 & 0 & 0 & -13.79 & -11.53 \\
\hline 50 & 0 & 0 & -29.41 & +38.46 & +100 & +60 & -6.89 & +26.92 \\
\hline 100 & -9.09 & 0 & -17.64 & +43.84 & +200 & +60 & -6.89 & +3.84 \\
\hline \multicolumn{9}{|c|}{ Analysis of accumulated elements in the fruit (\%) } \\
\hline \multirow{2}{*}{ Concentration (ppm) } & \multicolumn{2}{|c|}{$\mathrm{Ca}$} & \multicolumn{2}{|c|}{$\mathrm{Mg}$} & \multicolumn{2}{|c|}{$\mathrm{Na}$} & \multicolumn{2}{|c|}{$\mathrm{K}$} \\
\hline & E & $\mathrm{F}$ & $\mathrm{E}$ & $\mathrm{F}$ & E & $\mathrm{F}$ & $\mathrm{E}$ & $\mathrm{F}$ \\
\hline 25 & -2.85 & -40 & +1000 & +85.71 & -11.11 & +11.94 & -2.77 & +0.05 \\
\hline 50 & +5.71 & -32 & +750 & +149.25 & +20 & -10.44 & +11.11 & -5.88 \\
\hline 100 & -5.71 & +94 & +350 & 0 & +42.22 & -12.93 & +5.55 & -17.64 \\
\hline
\end{tabular}

* Mean of three repetitions. Application: E: edaphic; F: foliar; () gray color refers to an increase; (0) zero result means the value remains the same as the control; (100) the result hundred means that the value represents twice the result obtained in the control.

the other treatments and the control, demonstrating the 10fold increase in the bioaccumulation of this element (Figure $5, \mathrm{EMg}$ ). Regarding sodium, it was observed that, at an application of $100 \mathrm{ppm}$, there was an increase of $42.22 \%$ in the concentration of this element in the fruit compared to the control treatment (Figure 5, ENa). On the contrary, it also increased calcium concentrations by a $5.71 \%$ when $50 \mathrm{ppm}$ of phytonanoparticles are applied at the root level compared to the control (Figure 5, ECa), however, when evaluating the potassium element, no significant differences were demonstrated compared to the control treatment (Figure 5, EK) (Table 1).

Regarding the foliar application of different concentrations of phytonanoparticles, an increase of $85.71 \%$ of the magnesium element was observed in the fruit when $25 \mathrm{ppm}$ was applied, as well as an increase in calcium and sodium of $94 \%$ and $11.94 \%$, when applying 100 and $25 \mathrm{ppm}$, respectively (Figure 5, FCa-FNa), showing significant statistical differences with respect to the control treatment. However, there are no significant differences in the bioaccumulation of the potassium element with respect to the control (Figure 5, FK) (Table 1).

It was shown that magnesium is the element with the highest accumulation in both forms of application (Figure 5); however, a higher concentration of this element was demonstrated when the application is at the foliar level. $\mathrm{Li}$ et al. [25] reported that nonglandular trichomes (NGTs) were particularly important for foliar $\mathrm{Zn}$ absorption and moved across the cuticle before accumulating in the walls of the epidermal cells. Once absorbed, the $\mathrm{Zn}$ accumulated in the walls of the epidermal and the vascular cells and trichome bases of both leaf sides, with the bundle sheath extensions. The said saturation affects photosynthetic efficiency and therefore impacts flower formation and fruiting.

Also, Guo et al. [26] stated that the bioaccumulation of $\mathrm{Mg}$ participates in some signaling pathways for hormone 

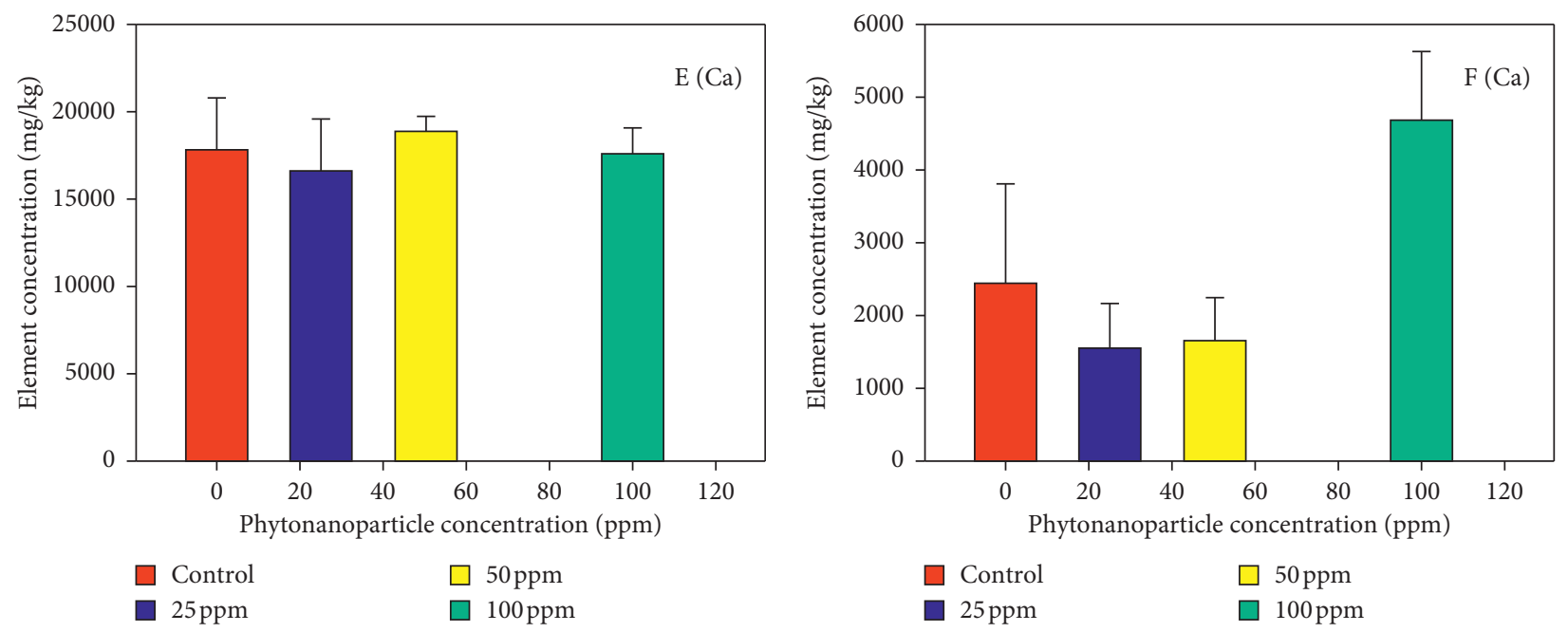

(a)

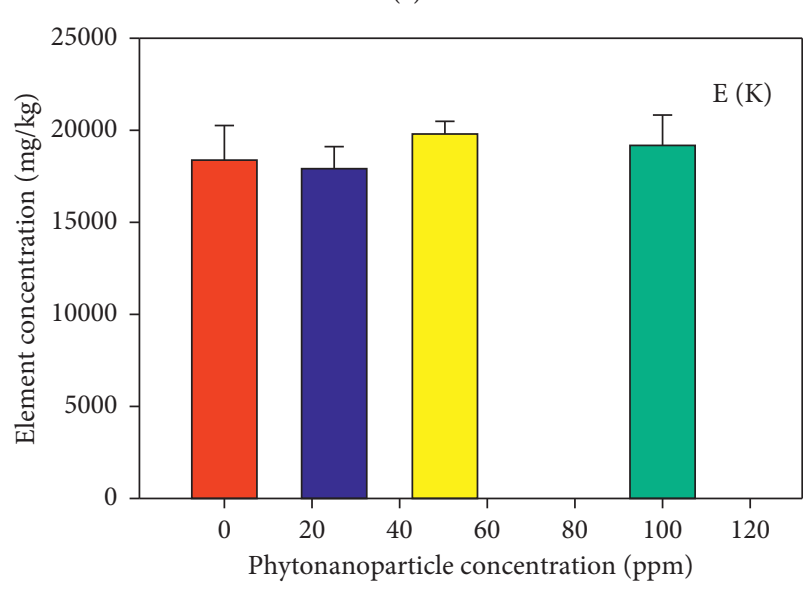

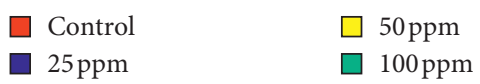

(c)

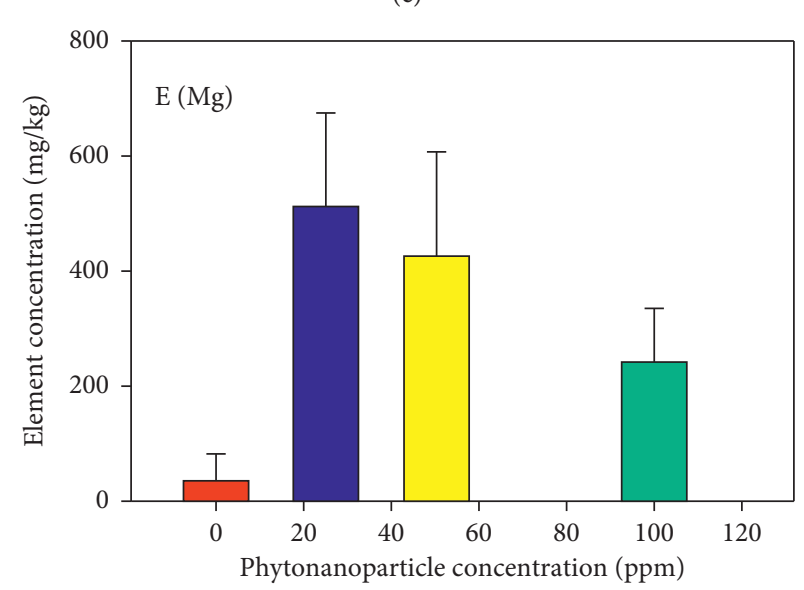

$\square$ Control

口 $25 \mathrm{ppm}$

$\square 100 \mathrm{ppm}$ $\square 50 \mathrm{ppm}$

$\square 100 \mathrm{ppm}$ $\square 50 \mathrm{ppm}$
$\square 100 \mathrm{ppm}$

(e)

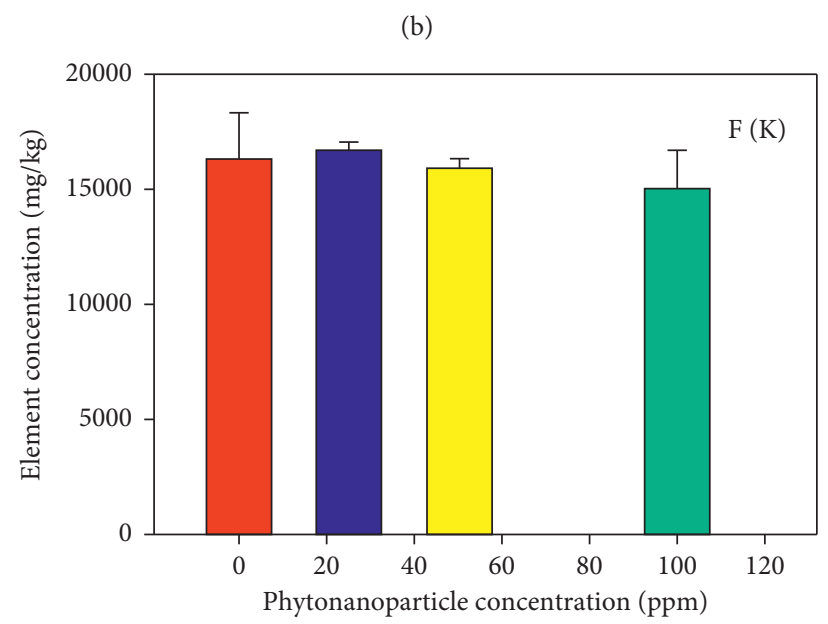

$\square$ Control

$25 \mathrm{ppm}$

$\square 100 \mathrm{ppm}$

(d)

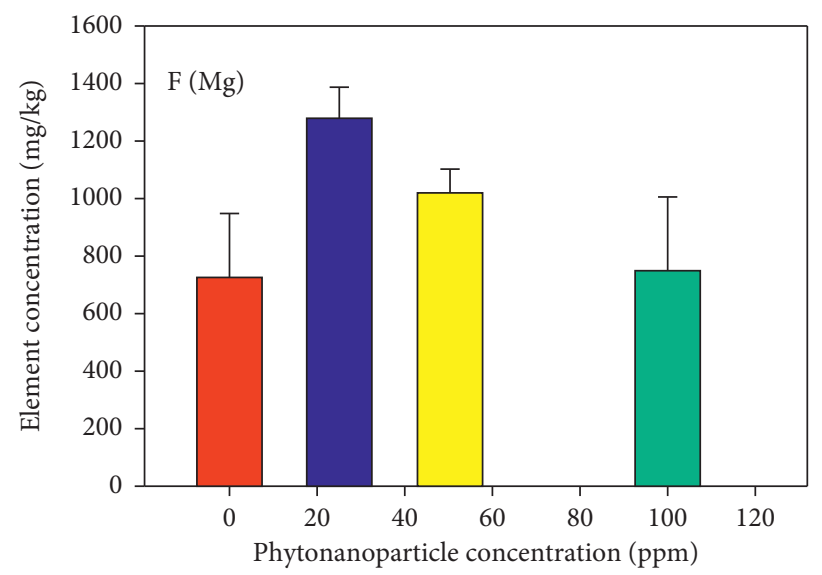

$\begin{array}{ll}\square \text { Control } & \square 50 \mathrm{ppm} \\ \square 25 \mathrm{ppm} & \square 100 \mathrm{ppm}\end{array}$

(f)

Figure 5: Continued. 


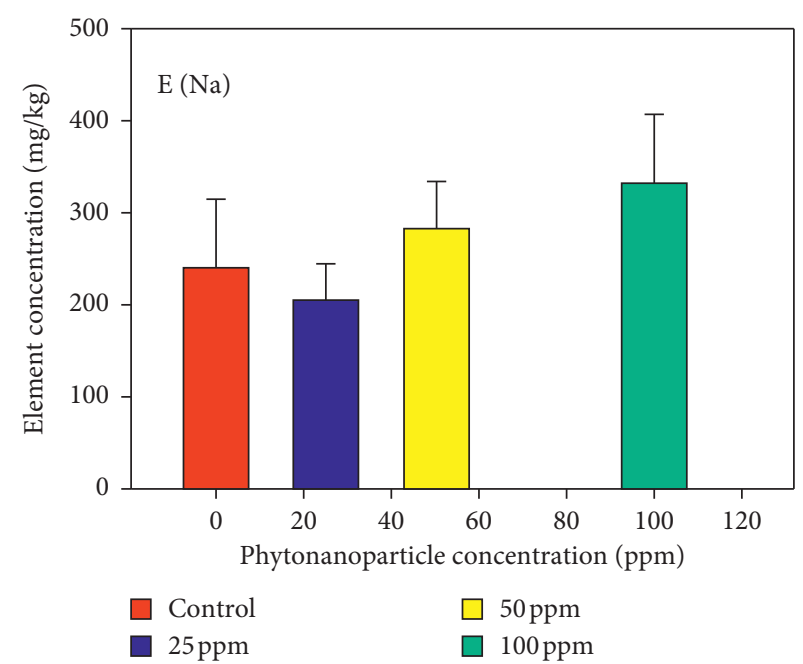

(g)



(h)

FiguRE 5: Evaluation of the accumulation of mineral elements in the fruits of tomato plants (Solanum lycopersicum) in relation to the effect of $\mathrm{ZnO}$ phytonanoparticles with the Moringa oleifera extract. Mean of three repetitions with $( \pm)$ standard error. Application: E: edaphic; F: foliar.

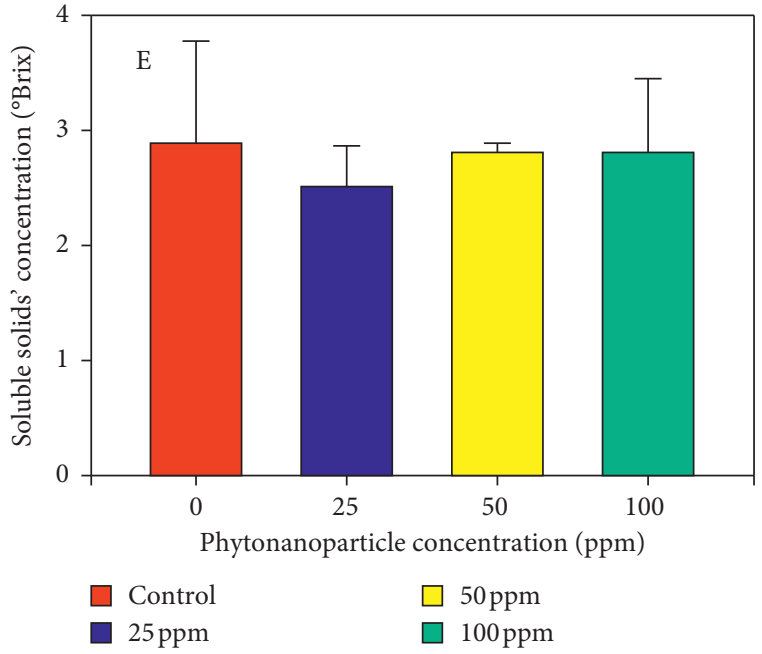

(a)

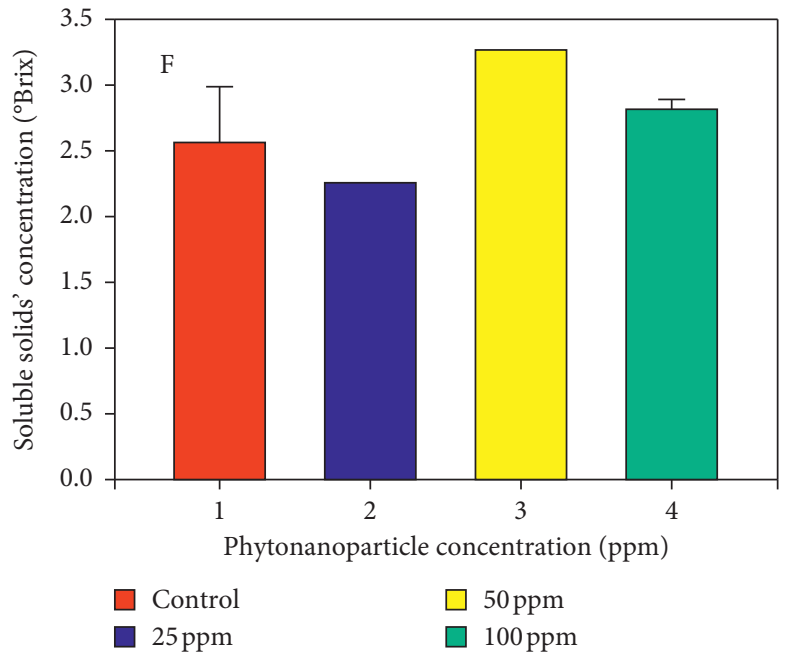

(b)

FIGURE 6: Quantification of total soluble solids in fruits of tomato plants (Solanum lycopersicum) in relation to the effect of ZnO phytonanoparticles with the Moringa oleifera extract. Mean of three repetitions with $( \pm)$ standard error. Application: E: edaphic; F: foliar.

production that participate in the carbon fixation, perspiration, accumulation starch, sugar metabolism, and ion up taking, important biological processes to the growth of plants [27].

According to the aforementioned, the significant increase in magnesium identified in this research work is a very important finding, since magnesium is a critical mineral in the human body and is involved in $\sim 80 \%$ of known metabolic functions. It is currently estimated that $60 \%$ of adults do not achieve the average dietary intake (ADI) and $45 \%$ are magnesium deficient, a condition associated with disease states like hypertension, diabetes, and neurological disorders, to name a few $[28,29]$.
On the contrary, in the present research work, the highest bioaccumulated concentrations of the elements calcium and sodium were observed, when phytonanoparticles were applied in a foliar way (Figure 5). Pérez-Labrada et al. [30] discovered that foliar application nanoparticles establish energetic interactions, demonstrating greater accumulation of cationic mineral elements such as $\mathrm{Na}^{+}$and $\mathrm{Ca}^{+}$.

In relation to calcium, Tien et al. [31] demonstrated that forms of calcium regulate physiological processes such as the secretions of airway epithelia and exocrine glands, the contraction of smooth muscles, and the excitability of neurons; therefore, it is important to have natural sources that provide calcium. 
Thus, the increase in calcium in the fruit generates great benefits at a commercial level, since it provides the fruit with more resistance during postharvest handling, even more important if we speak of fruits as perishable as the tomato [32]. As previously mentioned, Sinha et al. [33] identified that calcium $(2.0 \%)$ enhanced the storage life of plum fruits by reducing physiological loss in weight (PLW), total sugars and pectin methylesterase (PME), and cellulase activities; delaying the development of fruit color and anthocyanin; and retaining sensory quality, firmness, and total sugars in plum fruits. Also, Hyodo et al. [34] identified that the Ca-binding pectin and hairy pectin in skin cell layers are important for intercellular and tissue-tissue adhesion. Maintenance of the globular form and softening of tomato fruit may be regulated by the arrangement of pectin structures in each tissue; therefore, by increasing the calcium concentrations in the fruit, it improves the turgidity and texture of the fruit $[35,36]$.

On the contrary, the importance of sodium in fruits is also evident, since Stamler et al. [37] mentioned that controlled and low consumption of sodium, from natural sources, such as fruits, generates an osmotic balance of blood pressure [38].

Moreover, when evaluating the total soluble solids, an increase of $26.92 \%$ was observed with respect to the control, when $50 \mathrm{ppm}$ of phytonanoparticles was applied in a foliar way (Figure 6) (Table 1). It is important because it indicates the amount of sugar (sucrose) present in the fruit, as well as the freshness and the state of maturity of the same; this variable determines the decision-making for the direction of the fruit before a chain of agroindustrial transformation [39].

In this sense, in the present research work, it has been shown that the application of phytonanoparticles benefits the accumulation of elements such as $\mathrm{Mg}, \mathrm{Na}$, and $\mathrm{Ca}$ in the fruit, indicating that the stomata were an important pathway for the foliar absorption of $\mathrm{ZnO}$ in the plant, due to the retention and slow release of phytonanoparticles [27]; however, with an edaphic application, the direction of the compounds through the root system is guaranteed. This highlights that the slow-releasing nanofertilizer improves plant physiological properties and some nutritional parameters [29].

In this sense, fruits and vegetables (FVs) are recognized as healthy constituents of diet and a sustainable solution to the existing twin burden of micronutrient deficiencies [27]. In general, FVs are nutrient dense foods low in energy, containing varying amounts of vitamins and minerals including sodium, iron, zinc, potassium, calcium, magnesium, and fiber [27]. These are abundantly rich in phytochemicals that function as antioxidants, antiatherosclerotic, and antiinflammatory agents. Some studies have correlated the health benefits of FVs in relation to cardiovascular disease, obesity, and diabetes [34].

According to the aforementioned, it is important to state that the phytonanoparticles increase the concentration of micronutrients in the fruits $[9,40]$. Likewise, all benefits of phytonanoparticles are attributed to the antioxidant activity (AOA) of extracts from plant leaves because of impacts on the kinetics of photosynthesis, the size of the formed nanoparticles, and the stability of their nanosuspensions, due to the fact that the leaf extracts contain a wide range of biomolecules and metabolites, such as terpenoids, vitamins, polysaccharides, proteins, amino acids, alkaloids, (poly) phenolic compounds, aromatic amines, tannins, saponins, ketones, aldehydes, flavonoids, organic acids, enzymes, which act as reducing agents and stabilizer [19, 27, 41].

\section{Conclusion}

In conclusion, it was shown that application of phytonanoparticles in plants may help to optimize fertilization strategies, for maintaining important physiological processes such as net of micro- and macronutrients assimilation that is required for optimal plant growth, yield, and fruits quality by what is known to regulate the mechanisms of homeostasis in higher plants at the level of the cellular function. On the contrary, the phytonanoparticles induced the increase of magnesium, calcium, and sodium in fruits, considering that these minerals play an important role in regulating the biological functions of the consumer.

\section{Data Availability}

The data used to support the findings of this study are included within the article.

\section{Conflicts of Interest}

The authors declare that they have no conflicts of interest.

\section{References}

[1] T. L. Botha, E. E. Elemike, S. Horn, D. C. Onwudiwe, J. P Giesy, and V Wepener, "Cytotoxicity of Ag, Au and Ag$\mathrm{Au}$ bimetallic nanoparticles prepared using golden rod (Solidago canadensis) plant extract," Scientific Reports, vol. 9, no. 1, p. $4169,2019$.

[2] C. Tiloke, K. Anand, R. M. Gengan, and A. A. Chuturgoon, "Moringa oleifera and their phytonanoparticles: potential antiproliferative agents against cancer," Biomedicine \& Pharmacotherapy, vol. 108, pp. 457-466, 2018.

[3] R. C. Fierascu, A. Ortan, S. M. Avramescu, and I. Fierascu, "Phyto-nanocatalysts: green synthesis, characterization, and applications," Molecules, vol. 24, no. 19, p. 3418, 2019.

[4] D. Bharathi and V. Bhuvaneshwari, "Evaluation of the cytotoxic and antioxidant activity of phyto-synthesized silver nanoparticles using Cassia angustifolia flowers," BioNanoScience, vol. 9, no. 1, pp. 155-163, 2019.

[5] M. C. Mândru, D. Hoza, and S. Cristea, "Pathogens with economic importance for tomato crops growing in the field and their control," Scientific Papers. Series B, Horticulture, vol. 62, pp. 499-505, 2018.

[6] S. K. Chaudhuri and L. Malodia, "Biosynthesis of zinc oxide nanoparticles using leaf extract of Calotropis gigantea: characterization and its evaluation on tree seedling growth in nursery stage," Applied Nanoscience, vol. 7, no. 8, pp. 501-512, 2017.

[7] A. Abdelmoteleb, B. Valdez-Salas, and M. Carrillo, D. González-Mendoza and D. D. Hernandez, Green synthesis of silver nanoparticles using pluchea sericea a native plants from Baja California, Mexico and their potential application 
as antimicrobials," Iranian Journal of Science and Technology, Transactions A: Science, vol. 42, no. 2, pp. 457-463, 2018.

[8] V. Mendez-Trujillo, B. Valdez-Salas, M. Carrillo-Beltran et al., "Green synthesis of bimetallic nanoparticles from prosopis juliflora (sw) DC, and its effect against cotton mealybug, phenacoccus solenopsis (Hemiptera: pseudococcidae)," Phyton, vol. 88, no. 3, pp. 269-275, 2019.

[9] S. Tao, R. Pang, C. Chen, X. Ren, and S. Hu, "Synthesis, characterization and slow release properties of O-naphthylacetyl chitosan," Carbohydrate Polymers, vol. 88, no. 4, pp. 1189-1194, 2012.

[10] J. Santhoshkumar, S. Rajeshkumar, and S. Venkat Kumar, "Phyto-assisted synthesis, characterization and applications of gold nanoparticles-a review," Biochemistry and Biophysics Reports, vol. 11, pp. 46-57, 2017.

[11] J. I. García-López, G. Niño-Medina, E. Olivares-Sáenz et al., "Foliar application of zinc oxide nanoparticles and zinc sulfate boosts the content of bioactive compounds in habanero peppers," Plants, vol. 8, no. 8, p. 254, 2019.

[12] K. Johansen, M. J. L. Morton, Y. M. Malbeteau et al., "Unmanned aerial vehicle-based phenotyping using morphometric and spectral analysis can quantify responses of wild tomato plants to salinity stress," Frontiers in Plant Science, vol. 10, p. 370, 2019.

[13] E. González-Terreros, V. M. Ruiz-Valdiviezo, A. GalvánVelázquez, M. O. Franco Hernadez, M. Luna-Guido, and L. Dendooven, "Heavy metals in mine-tailing soil mixtures cultivated with Ricinus communis L. polish," Journal of Environmental Studies, vol. 27, no. 5, 2018.

[14] S. Bedbabis, B. Ben Rouina, M. Boukhris, and G. Ferrara, "Effects of irrigation with treated wastewater on root and fruit mineral elements of Chemlali olive cultivar," The Scientific World Journal, vol. 2014, Article ID 973638, 8 pages, 2014.

[15] M. Sagar, C. Chervin, I. Mila et al., "SlARF4, an auxin response factor involved in the control of sugar metabolism during tomato fruit development," Plant Physiology, vol. 161, no. 3, pp. 1362-1374, 2013.

[16] R. Javed, M. Usman, B. Yücesan, M. Zia, and E. Gürel, "Effect of zinc oxide $(\mathrm{ZnO})$ nanoparticles on physiology and steviol glycosides production in micropropagated shoots of Stevia rebaudiana Bertoni," Plant Physiology and Biochemistry, vol. 110, pp. 94-99, 2017.

[17] D. Sharma, D. Maheshwari, G. Philip et al., "Formulation and optimization of polymeric nanoparticles for intranasal delivery of lorazepam using box-behnken design: in vitro and in vivo evaluation," BioMed Research International, vol. 2014, Article ID 156010, 14 pages, 2014.

[18] P. Ruiz-Romero, B. Valdez-Salas, D. González-Mendoza, and V. Mendez-Trujillo, "Antifungal effects of silver phytonanoparticles from Yucca shilerifera against strawberry soil-borne pathogens: Fusarium solani and Macrophomina phaseolina," Mycobiology, vol. 46, no. 1, pp. 47-51, 2018.

[19] N. Y. Stozhko, M. A. Bukharinova, E. I. Khamzina, A. V. Tarasov, M. B. Vidrevich, and K. Z. Brainina, "The effect of the antioxidant activity of plant extracts on the properties of gold nanoparticles," Nanomaterials, vol. 9, no. 12, p. 1655, 2019.

[20] N. A. Anjum, A. Sofo, A. Scopa et al., "Lipids and proteinsmajor targets of oxidative modifications in abiotic stressed plants," Environmental Science and Pollution Research, vol. 22, no. 6, pp. 4099-4121, 2015.

[21] P. Punia, M. K. Bharti, S. Chalia et al., "Recent advances in synthesis, characterization, and applications of nanoparticles for contaminated water treatment-a review," Ceramics International, vol. 47, no. 2, pp. 1526-1550, 2020.

[22] O. Duman and S. Tunç, "Electrokinetic and rheological properties of Na-bentonite in some electrolyte solutions," Microporous and Mesoporous Materials, vol. 117, no. 1-2, pp. 331-338, 2009.

[23] B. Méndez-Argüello, I. Vera-Reyes, E. Mendoza-Mendoza, L. A. García-Cerda, B. A. Puente-Urbina, and R. H. Lira Saldívar, "Promoción del crecimiento en plantas de Capsicum annuum por nanopartículas de óxido de zinc," Nova Scientia, vol. 8, no. 17, pp. 140-156, 2016.

[24] A. M. Santos-Espinoza, D. González-Mendoza, V. M. RuizValdiviezo et al., "Changes in the physiological and biochemical state of peanut plants (Arachis hypogaea L.) induced by exposure to green metallic nanoparticles," International Journal of Phytoremediation, vol. 23, no. 7, pp. 747-754, 2020.

[25] C. Li, P. Wang, A. Van der Ent et al., "Absorption of foliarapplied $\mathrm{Zn}$ in sunflower (Helianthus annuus): importance of the cuticle, stomata and trichomes," Annals of Botany, vol. 123, no. 1, pp. 57-68, 2019.

[26] W. Guo, S. Chen, N. Hussain et al., "Magnesium stress signaling in plant: just a beginning," Plant Signaling \& Behavior, vol. 10, no. 3, Article ID e992287, 2015.

[27] Y. Sun, L. Chen, Y. Bao et al., "The applications of morphology controlled $\mathrm{ZnO}$ in catalysis," Catalysts, vol. 6, no. 12, p. 188, 2016.

[28] K. Krishnaswamy and R. Gayathri, "Nature's bountiful gift to humankind: vegetables \& fruits \& their role in cardiovascular disease \& diabetes," Indian Journal of Medical Research, vol. 148 , no. 5 , p. 569, 2018.

[29] M. Kolenčík, D. Ernst, M. Komár et al., "Effect of foliar spray application of zinc oxide nanoparticles on quantitative, nutritional, and physiological parameters of foxtail millet (Setaria italica L.) under field conditions," Nanomaterials, vol. 9, no. 11, p. 1559, 2019.

[30] F. Pérez-Labrada, E. R. López-Vargas, H. Ortega-Ortiz, G. Cadenas-Pliego, A. Benavides-Mendoza, and A. JuárezMaldonado, "Responses of tomato plants under saline stress to foliar application of copper nanoparticles," Plants, vol. 8, no. 6, p. 151, 2019.

[31] J. Tien, C. J. Peters, X. M. Wong et al., "A comprehensive search for calcium binding sites critical for TMEM16A calcium-activated chloride channel activity," Elife, vol. 3, Article ID e02772, 2014.

[32] B. Hocking, S. D. Tyerman, R. A. Burton, and M. Gilliham, "Fruit calcium: transport and physiology," Frontiers in Plant Science, vol. 7, p. 569, 2016.

[33] A. Sinha, S. K. Jawandha, P. P. S. Gill, and H. Singh, Influence of pre-harvest sprays of calcium nitrate on storability and quality attributes of plum fruits," Journal of Food Science and Technology, vol. 56, no. 3, pp. 1427-1437, 2019.

[34] H. Hyodo, A. Terao, J. Furukawa et al., "Tissue specific localization of pectin- $\mathrm{Ca}^{2+}$ cross-linkages and pectin methylesterification during fruit ripening in tomato (Solanum lycopersicum)," PLoS One, vol. 8, no. 11, Article ID e78949, 2013.

[35] D. Aldon, M. Mbengue, C. Mazars, and J. P. Galaud, "Calcium signalling in plant biotic interactions," International Journal of Molecular Sciences, vol. 19, no. 3, p. 665, 2018.

[36] T. Martins, M. Evans, H. Woolfenden, and R. Morris, "Towards the physics of calcium signalling in plants," Plants, vol. 2, no. 4, pp. 541-588, 2013.

[37] J. Stamler, Q. Chan, M. L. Daviglus et al., "Relation of dietary sodium (salt) to blood pressure and its possible modulation by 
other dietary factors," Hypertension, vol. 71, no. 4, pp. 631-637, 2018.

[38] P. Kuppusamy, M. M. Yusoff, G. P. Maniam, and N. Govindan, "Biosynthesis of metallic nanoparticles using plant derivatives and their new avenues in pharmacological applications-an updated report," Saudi Pharmaceutical Journal, vol. 24, no. 4, pp. 473-484, 2016.

[39] S. D. Rowland, K. Zumstein, H. Nakayama et al., "Leaf shape is a predictor of fruit quality and cultivar performance in tomato," New Phytologist, vol. 226, no. 3, pp. 851-865, 2020.

[40] S. Wang, M. Li, K. Liu et al., "Effects of Zn, macronutrients, and their interactions through foliar applications on winter wheat grain nutritional quality," PLoS One, vol. 12, no. 7, Article ID e0181276, 2017.

[41] S. Saif, A. Tahir, and Y. Chen, "Green synthesis of iron nanoparticles and their environmental applications and implications," Nanomaterials, vol. 6, no. 11, p. 209, 2016. 